\title{
On the Concept and Conservation of Critical Natural Capital
}

\section{Tyler DesRoches}

To cite this article: C. Tyler DesRoches (2020): On the Concept and Conservation of Critical Natural Capital, International Studies in the Philosophy of Science, DOI: 10.1080/02698595.2020.1788347

To link to this article: https://doi.org/10.1080/02698595.2020.1788347

\section{Published online: 06 Aug 2020.}

Submit your article to this journal $\pi$

Q View related articles $\sqsubset$

View Crossmark data $־$ 


\title{
On the Concept and Conservation of Critical Natural Capital
}

\author{
C. Tyler DesRoches (i)
}

School of Sustainability, School of Historical, Philosophical and Religious Studies, and Center for the Study of Economic Liberty, Arizona State University, Tempe, AZ, USA

\begin{abstract}
Ecological economics is an interdisciplinary science that is primarily concerned with developing interventions to achieve sustainable ecological and economic systems. While ecological economists have, over the last few decades, made various empirical, theoretical, and conceptual advancements, there is one concept in particular that remains subject to confusion: critical natural capital. While critical natural capital denotes parts of the environment that are essential for the continued existence of our species, the meaning of terms commonly associated with this concept, such as 'non-substitutable' and 'impossible to substitute,' require a clearer formulation then they tend to receive. With the help of equations and graphs, this article develops new definite account of critical natural capital that makes explicit what it means for objective environmental conditions to be essential for continued existence. The second main part of this article turns to the question of formally modelling the priority of conserving critical natural capital. While some ecological economists have maintained that, beyond a certain threshold, critical natural capital possesses absolute infinite value, absolute infinite utility models encounter significant problems. This article shows that a relative infinite utility model provides a better way to model the priority of conserving critical natural capital.
\end{abstract}

\section{KEYWORDS}

philosophy of ecological economics; critical natural capital; causation;

sustainability; conservation; non-standard decision theory

\section{Introduction}

Ecological economics is an interdisciplinary science that emerged as a formal institution in the late 1980s, with its origins extending back to Nicholas Georgescu-Roegen's (1971) The Entropy Law and Economic Processes. ${ }^{1}$ This policy-oriented field is primarily concerned with developing economic policies and interventions that achieve sustainable ecological and economic systems. Some ecological economists have gone so far as to claim that their field of research is the only one poised to address the problem of human survival in the coming centuries, mainly because their field explicitly recognises the various interdependencies between biophysical, social, and economic systems (Gowdy and Erickson 2005). Others have described the transition from neo-classical economics to ecological economics as a requisite Kuhnian paradigm shift from normal science to post-normal

CONTACT C. Tyler DesRoches tyler.desroches@asu.edu E School of Sustainability, Arizona State University, PO Box 875502, Tempe, AZ, USA 
science (Daly and Townsend 1993; Functowicz and Ravetz 1994; Tacconi 1998; Illge and Schwarze 2009).

While ecological economists have, over the last few decades, made various empirical, theoretical, and conceptual advancements, at least one concept remains subject to significant confusion: 'critical natural capital' (Brand 2009). ${ }^{2}$ This concept is most well-known for its role in the canonical debate between weak and strong sustainability. 'Weak sustainability' is traditionally associated with the work of Robert M. Solow $(1986,1993 a)$. On this view, sustainability requires that the total stock of capital, which consists of manufactured, human, and natural capital, is held constant across time and between generations. ${ }^{4}$ Manufactured capital denotes the traditional produced means of production, such as machines, factories, and tools; human capital includes items such as knowledge, technology, and institutions; and natural capital consists of various renewable and non-renewable resources, including non-market phenomena such as ecosystems. On this view, agents may deplete natural capital provided that it is replaced by enough manufactured capital (Stern 1997). As Solow states,

Resources are ... fungible in a certain sense. They can take the place of each other. That is extremely important because it suggests that we do not owe the future any particular thing. There is no specific object that the goal of sustainability, the obligation of sustainability, requires us to leave untouched $(1993 \mathrm{~b}, 181)$.

On this view, what matters is not that any particular stock of capital is depleted but that the overall stock of capital, which constitutes the productive capacity of an economy, is nondiminishing over time. ${ }^{5}$

'Strong sustainability,' on the other hand, derives from the earlier work of David W. Pearce et al. (1989) and others, including Robert Costanza and Herman Daly (1992). The proponents of this view, which includes most ecological economists, generally argue that because natural and manufactured capital are complements rather than substitutes, sustainable development requires that each stock of capital should be held constant, independently.

The most significant argument given to support strong sustainability is the argument from critical natural capital. ${ }^{6}$ This argument begins with the premise that there exists a special set of environmental conditions required for the continued existence of our species (Victor 1991; Folke et al. 1994; Stern 1997; Barbier 2011). ${ }^{7}$ These conditions are denoted by the concept of critical natural capital. If one presumes a commitment to sustainability, then, the objects denoted by this concept must be sustained in kind, a conclusion that is generally thought to be incompatible with Solow's assertion above - that 'no specific object need be left untouched.'

While critical natural capital plays a crucial role for ecological economics, especially for the debate between weak and strong sustainability, the meaning of terms commonly associated with the concept, such as 'non-substitutable,' 'near-impossible to substitute,' and 'essential for continued existence' remain obscure. The first main section of this article grapples with the various definition types of critical natural capital and argues that each of them is deficient in some way. Section 3 then proposes a new account of the environmental conditions required for continued existence based on equations and graphs, a structural framework originally developed by computer scientists and further refined by philosophers (Pearl 2000 [2009]; Halpern and Pearl 2000; Hitchcock 2001). 
This account makes explicit what it means for objective environmental conditions to be essential for the continued existence of an agent or group. Moreover, the account is shown to be consistent with relevant empirical evidence concerning the objects and processes widely considered to be instances of critical natural capital (Rockström et al. 2009a, 2009b).

Section 4 turns to the question valuing critical natural capital. While some ecological economists have claimed that, beyond some threshold, critical natural capital possesses absolute infinite value, I will follow others, arguing that absolute infinite utility models run into significant problems in the context of modelling conservation decisions (Colyvan, Justus, and Regan 2010). Following Paul Bartha (2007) and Bartha and DesRoches (2017), I will show that a relative infinite utility model provides a better way to model the priority of conserving critical natural capital. Section 5 concludes.

\section{What is Critical Natural Capital?}

The concept of critical natural capital was first developed by members of the London Centre for Environmental Economics in the late 1980s to denote parts of the natural environment essential for basic life support (Victor 1991; Stern 1997). Over the past several decades, the concept has been popularised by ecological economists, particularly as it relates to the debate between weak and strong sustainability, but also as a significant concept to be explained on its own terms. Critical natural capital has been defined variously (Hueting and Reijnders 1998; de Groot et al. 2003; Ekins et al. 2003; Farley 2008; Barbier 2011; Pelenc and Ballet 2015). Consider the following sample set of definitions: ${ }^{8}$

1. That set of environmental resources which performs important environmental functions and for which no substitutes in terms of human, manufactured, or other natural capital currently exist (Ekins et al. 2003).

2. Critical natural capital consists of assets, stock levels, or quality levels that are: (1) highly valued; and either (2) essential to human health, or (3) essential to the efficient functioning of life support systems, or (4) irreplaceable or non-substitutable for all practical purposes (e.g. because of antiquity, complexity, specialisation, or location) (English Nature 1994).

3. Vital parts of the environment that contribute to life support systems, biodiversity, and other necessary functions / as keystone species and processes (Turner 1993).

4. The degree to which natural capital is threatened or vulnerable (de Groot et al. 2006, 221).

5. Ecological functioning of natural systems above certain thresholds of degradation in order to conserve the capacity of natural capital to provide the services which are critical for human existence and well-being (Pelenc and Ballet 2015). ${ }^{9}$

While this non-exhaustive list might lead some to conclude that critical natural capital is especially confused, these definitions appear to cluster around three types. A-type definitions generally pick out some non-empty set of environmental conditions that must be satisfied for the continued existence of our species (Victor 1991; Folke et al. 1994; Stern 1997; Barbier 2011); B-type definitions, tend to emphasise a special or distinctive subjective value judgement that makes some instance of natural capital critical 
(Chiesura and de Groot 2003). For example, some part of nature might be judged as 'sacred' by some group without being essential for continued existence. Both A and Btype definitions identify parts of the natural environment as critical natural capital but disagree on what makes them so. Under most A-type definitions, natural capital is critical if and only if it is required for the continued existence of some referent group. For B-type definitions, some instance of natural capital is critical if and only if it is 'highly valued' or 'sacred' to some group.

Both A and B-type definitions appear to be deficient in some way. A-type definitions generally ignore values and, therefore, it is difficult to see how ecological economists might model the conservation of critical natural capital, a project that requires value judgements. On the other hand, B-type definitions take values seriously, but perhaps too seriously. On this definition type, any instance of natural capital qualifies as critical so long as an agent assigns it with a 'high value.' This definition type risks casting the net too wide, thus making too many parts of the environment critical natural capital. Moreover, to claim that some part of the environment is critical natural capital if and only if it is 'highly valued' or 'sacred' begs the question about the exact nature of such special value ascriptions and their relationship to ordinary finite values.

Perhaps the most promising definition type of critical natural capital contains elements of both A and B-type definitions. Jérôme Pelenc and Jérôme Ballet provided one recent example of this third hybrid definition type when they state, 'the criticality of the ecosystem services provided by critical natural capital is dependent not only on ecological criteria, but also on the values espoused by society' $(2015,38)$. In general, we might suppose that hybrid A-B type definitions entail that any instance of natural capital is critical if and only if the following two conditions are satisfied:

(1) it is required for continued existence of some agent or group

(2) it is 'highly valued' by some agent or group

Of course, conditions (1) and (2) can be specified in numerous ways. With respect to Condition (1), no A-B type definition has yet made explicit - in definite terms - what it means for some environmental conditions to be required for continued existence for some agent or group. Ecological economists often assert that there is a subclass of natural capital for which there are no substitutes, yet many questions remain. Why exactly do the objects denoted by critical natural capital have no substitutes? What conditions, if any, would need to be satisfied for another object to serve as a potential substitute for an instance of critical natural capital? What factor makes critical natural capital distinctive from other non-essential parts of the environment? Any defensible A-B type definition of critical natural capital must answer such questions, which I will consider as desiderata for specifying Condition 1. Moreover, any defensible definition of critical natural capital should be consistent with relevant empirical evidence concerning objects and processes widely considered to be instances of critical natural capital.

The next section will show how equations and graphs make explicit what it means for some environmental conditions - what I term basic environmental conditions - to be essential for the continued existence of an agent or group. Section 4 will then turn towards the project of elucidating Condition 2, the distinctive kind of value assigned to critical natural capital. I will argue that while some ecological economists have suggested 
that, beyond a certain threshold, critical natural capital possesses absolute infinite value, this value ascription is problematic in the context of formally modelling conservation decisions. I will show that a relative infinite utility model provides a better way to model the priority of conserving critical natural capital.

\section{Specifying Critical Natural Capital with Equations and Graphs}

The objective of this section is to specify Condition (1). I will use the term 'basic environmental conditions' to reflect the familiar idea that agents can only exist within a certain range of physical or material conditions. It is to be remarked that such conditions are always relative to a specific agent embedded in an external environment that includes a totality of factors, both biotic and physical at a particular time and place, and with a given level of technology. For simplicity, in what follows I will refer to such situated agents as merely 'agents.'

\subsection{Equations and Graphs: A Primer}

Before showing how equations and graphs can be used to formulate basic environmental conditions, it will be useful to show how this framework can be used to represent systems of causal knowledge generally. ${ }^{10}$

A causal model is a pair $\langle\gamma, \varepsilon>$ where $\gamma$ is a set of relevant variables and $\varepsilon$ is a set of equations that describe relationships among the variables that belong to $\gamma$. Let us begin with a simple example. Some $E$ is a binary value with possible values $E=0$ and $E=1$. These values represent the occurrence or non-occurrence of a specific event, e: $E=1$ represents the occurrence of e, and $E=0$ represents the non-occurrence of e. Suppose that $e$ represents the occurrence of a rainy day. Then $E=1$ represents the occurrence of rain and $E=0$ represents the non-occurrence of rain.

The set $\gamma$ contains both exogenous and endogenous variables. The former have their values determined by processes external to the model, while the latter have their values determined as a function of other variables in the model. The set $\varepsilon$ contains exactly one equation for each variable in $\gamma$. Corresponding to the distinction between exogenous and endogenous variables, $\varepsilon$ is comprised of two subsets, $\varepsilon_{\mathrm{x}}$ and $\varepsilon_{\mathrm{n}}$. All of the equations in $\varepsilon_{\mathrm{x}}$ take the simple form $X=x$ : they state the actual value of the variable in question as fixed by an external process. Equations in $\varepsilon_{\mathrm{n}}$ take the form

$$
Z=f_{z}(X, Y \ldots W) \text {. }
$$

Each such equation expresses the value of an endogenous variable as a function of the values of other variables in the set $\gamma$. Equation (1) means that if it were the case that $X$ $=\mathrm{x}, Y=\mathrm{y}, \ldots, W=\mathrm{w}$, then it would be the case that $Z=f_{z}(x, y, \ldots w)$. In other words, the dependent variable $Z$ depends counterfactually on the values of the variables $X, Y$ $\ldots \mathrm{W}$, and nothing else. Each of the variables $X, Y, \ldots, W$ on which $Z$ depends directly is termed a 'parent' of $Z$. Unlike endogenous variables, exogenous variables have no parents since their values are determined by factors outside the system.

A convenient feature of this framework is that a system of structural equations can be given an elegant graphical representation. ${ }^{11}$ As shown in Figure 1 below, variables form the nodes of a graph and these nodes are connected by arrows according to the following 
rule: an arrow is drawn from $X$ to $Z$ if and only if $X$ is a parent of $Z$. There is a 'directed path' from $X$ to $Z$ where there is a sequence of arrows that are lined up connecting $X$ with $Z$ (exogenous variables have no arrows directed to them).

Before moving on to specific examples, it will be useful to introduce some notation: $\neg$, $\vee, \wedge$, represent the following mathematical functions: $\neg X \equiv 1-X, X \vee Y \equiv \max \{X, Y\}, X \wedge Y$ $\equiv \min \{X, Y\}$. If $Z=X \vee Y$, then $Z$ will take the value of 1 if and only if either $X$ or $Y$ takes the value $1 . Z=X \wedge Y$, then $Z$ will take on the value of 1 if and only if $X$ takes the value of 1 and $Y$ takes the value of 1 . In other words, $Z$ is true if and only if $X$ is true and $Y$ is true. Let's begin with an example, depicted in Figure 1, that uses equations and a graph.

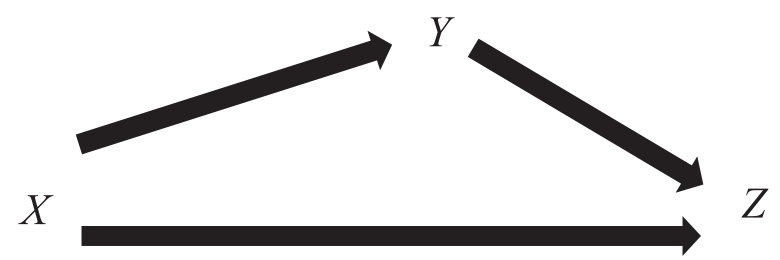

Figure 1. Raining on Fred's Field.

In this case, the variable $X=1$ corresponds to rain on Fred the Farmer's field; $X=0$ corresponds to no rain on Fred's field. $Y=1$ corresponds to Fred watering his field with an irrigation system; $Y=0$ corresponds to Fred not watering his field. $Z=1$ corresponds to Fred's crop surviving; $Z=0$ corresponds a crop failure. It should be clear that there are two routes whereby $X$ can influence $Z$ - one that goes directly to $Z$ and the other that goes through $Y$. The set of structural equations is as follows:

$$
\varepsilon: X=1 ; Y=\neg X ; Z=X \vee Y
$$

$X$ is an exogenous variable (whether it rains on Fred's field is not caused by any other variable in the set $\gamma$ ). The equation $Z=X \vee Y$ encodes the following counterfactual: if either $X$ or $S$ were to take the value of 1 - if it rained on Fred's field or Fred watered his crop - then his crop would survive. In this case, $\tau \varepsilon$ has the following unique solution:

$$
X=1 ; Y=0 ; Z=1 \text {. }
$$

It actually rained on the Fred's field; Fred did not water his field; the crop survived.

Now, suppose that it did not rain. The set of structural equations is as follows:

$$
\varepsilon: X=0 ; Y=\neg X ; Z=X \vee Y
$$

Again, $X$ is an exogenous variable. $\varepsilon$ has the following unique solution:

$$
X=0 ; Y=1 ; Z=1 \text {. }
$$

It did not rain; Fred watered his crop; and Fred's crop survived. It should be clear that the causal graph depicted in Figure 1 does not itself specify the actual values of any variables or even the nature of the dependence; this information is only contained in the set of structural equations that accompanies the graph. It should also be understood that each 
equation in $\varepsilon_{\mathrm{n}}$ encodes counterfactual information. For example, if it were the case that $X$ $=x, Y=y, \ldots, W=w$, then $\ldots Z=1$.

\subsection{Modelling Critical Natural Capital with Equations and Graphs}

As a first attempt, we might represent the basic environmental conditions for an agent with the following equations and graphs.

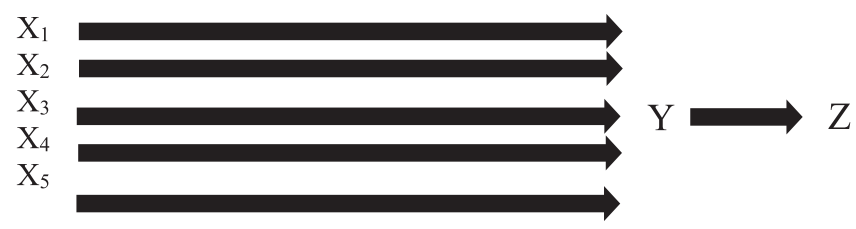

Figure 2. Five Basic Environmental Conditions.

$$
\varepsilon: X_{1}=1 ; X_{2}=1 ; X_{3}=1 ; X_{4}=1 ; X_{5}=1 ; Y=X_{1} \wedge X_{2} \wedge X_{3} \wedge X_{4} \wedge X_{5} ; Z=Y
$$

The graph in Figure 2 shows that every basic environmental condition, $X_{\mathrm{n}}$, is directed towards $Y$, a viable environment for the agent. In this case, a viable environment is identified with the occurrence of no more and no less than five basic environmental conditions. The basic environmental condition $X_{1}$, for example, might be a certain quantity and quality of water that meets the subsistence requirement of the agent at a particular time and place. Or, it could be a subsistence level of oxygen. The set of structural equations directly above imply that no basic environmental condition on its own is sufficient to cause a viable environment, $Y$, to take the value of 1 . Instead, $X_{1}, X_{2}, X_{3}, X_{4}, X_{5}$ are necessary and sufficient to bring about a viable environment for the agent. In other words, $Y=1$ if and only if $X_{1}=1, X_{2}=1, X_{3}=1, X_{4}=1, X_{5}=1$. Conveniently, these equations have a unique solution:

$$
\varepsilon: X_{1}=1 ; X_{2}=1 ; X_{3}=1 ; X_{4}=1 ; X_{5}=1 ; Y=1 ; Z=1
$$

This solution means that there is a subsistence quantity of each basic environmental condition that must be met for the continued existence of this particular agent. Jointly, the occurrence of each such condition causes a viable environment and, therefore, $Z$ takes the value of 1 . That is, the agent continues to exist. Counterfactually, we also know that if it were the case that any $X_{\mathrm{n}}=0$, then $Y=0$, and $Z=0$ : if any basic environmental condition were missing from what would otherwise be the agent's viable environment, then the agent would cease to exist (eventually). In this example, as with the previous one, we are assuming that every variable is binary: they take a value of 1 or $0 . Y=1$ if and only if the agent has a viable environment and $Y=0$ if and only if the agent does not have a viable environment. $Z$ represents either the continued existence of the agent $(Z=1)$ or her death $(Z=0) .{ }^{12}$

Of course, to claim that some agent depends on exactly five basic environmental conditions is entirely arbitrary. The agent might well depend on $n$ conditions, as depicted in Figure 3 below: 


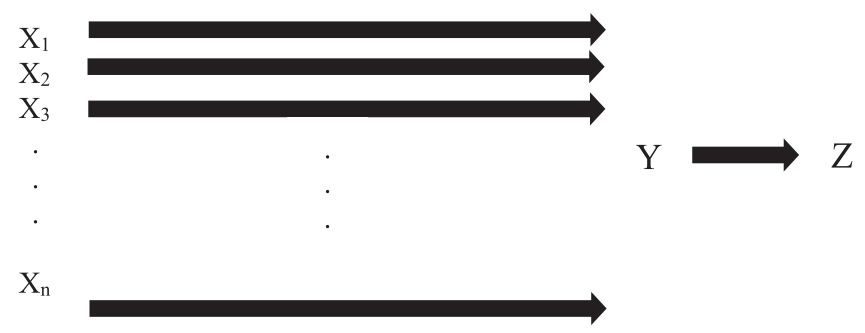

Figure 3. ' $n$ ' Basic Environmental Conditions.

$$
\varepsilon: X_{1}=1 ; X_{2}=1 ; X_{3}=1 ; \ldots X_{n}=1 ; Y=X_{1} \wedge X_{2} \wedge X_{3} \wedge \ldots \wedge X_{n} ; Z=Y
$$

The unique solution:

$$
\varepsilon: X_{1}=1 ; X_{2}=1 ; X_{3}=1 \ldots X_{n}=1 ; Y=1 ; Z=1 \text {. }
$$

In this case, a viable environment is identified with the occurrence of $n$ basic environmental conditions. As with the previous example, the set of structural equations implies that no single basic environmental condition is sufficient to cause $Y$ to take the value of 1. Instead, $X_{1}=1, X_{2}=1, X_{3}=1, \ldots, X_{n}=1$ are jointly necessary and sufficient to bring about a viable environment and, therefore, continued existence. It should be clear that the situation depicted in Figure 2 can be generalised from five to any number, $n$, of basic environmental conditions, with corresponding changes to the graph and set of structural equations.

Figures 2-3 show that the causal routes from every basic environmental condition to a viable environment, is a direct route. ${ }^{13}$ Basic environmental conditions are required for continued existence because they afford an objective causal role to the agent that is required and not available in any other kind of ecological condition.

There are no intermediate variables between basic environmental conditions, a viable environment, and the continued existence of a given agent. Basic environmental conditions have no substitutes because their causal properties are not multiply realisable at a particular time and place, with a given level of technology. If any of these elements time, place, or technology - were to change, then the agent's viable environment, the set of basic environmental conditions, may also change. Indeed, it is to be expected that viable environments will undergo constant change and, moreover, agents themselves are taken to be changing self-reproducing physical systems capable of modifying themselves, their technologies, and their environments (Lewontin 1983). As Daniel Dennett explains:

A tiger is viable now, in certain existing environments on our planet, but would not have been viable in most earlier days, and may become inviable in the future (as may all life on Earth, in fact). Viability is relative to the environment in which the organism must make its living. Without breathable atmosphere and edible prey - to take the most obvious conditions the organic features that make tigers viable today would be to no avail. And since environments are to a great extent composed of, and by, the other organisms extant, viability is a constantly changing property, a moving target, not a fixed condition $(1996,115)$. 
Viable environments possess what Dennett refers to as a 'moving target quality' and equations and graphs are sensitive to this quality. A somewhat artificial example will help to illustrate this point. Let us reasonably suppose that some quantity of water $\left(\mathrm{H}_{2} \mathrm{O}\right)$ - a subsistence level of water - is a basic environmental condition for specific agents. Since $\mathrm{H}_{2} \mathrm{O}$ is the only kind of molecule capable of executing a causal role required for the continued existence of agents, it qualifies as a basic environmental condition for these agents. Let us suppose that synthetic molecules are now developed and subsequently made available to agents. This technological innovation affords agents with the same objective causal role as $\mathrm{H}_{2} \mathrm{O}$. In this case, $\mathrm{H}_{2} \mathrm{O}$ would cease to be a basic environmental condition for such agents because the causal role it performs can now be realised in another kind of molecule. We can represent the introduction of these synthetic molecules - call them 'causal water' - with equations and graphs as follows, in Figure 4:

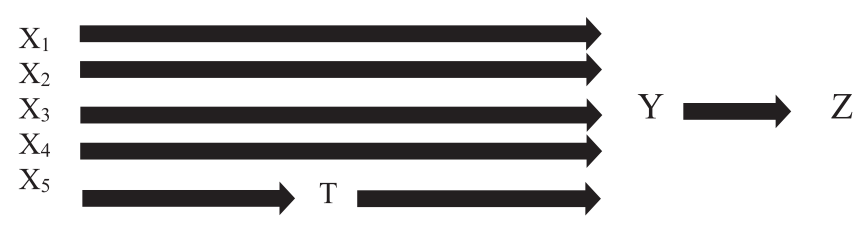

Figure 4. The Introduction of 'Causal Water'.

The set of structural equations is as follows:

$$
\begin{aligned}
\varepsilon: X_{1} & =1 ; X_{2}=1 ; X_{3}=1 ; X_{4}=1 ; X_{5}=0 ; T=\neg X_{5} ; Y \\
& =X_{1} \wedge X_{2} \wedge X_{3} \wedge X_{4} \wedge\left[X_{5} \vee T\right] ; Z=Y
\end{aligned}
$$

As with the previous example, every $X_{\mathrm{n}}$ is an exogenous variable. Let $X_{5}$ represent the subsistence level of $\mathrm{H}_{2} \mathrm{O}$ that would be available to the agent if there were no $T$ or 'causal water.' In contrast to the previous examples, $X_{5}=0$. Be that as it may, $T=\neg X_{5}$, and $Y=$ $X_{1} \wedge X_{2} \wedge X_{3} \wedge X_{4} \wedge\left[X_{5} \vee T\right]$. The solution to these equations is also unique:

$$
\varepsilon: X_{1}=1 ; X_{2}=1 ; X_{3}=1 ; X_{4}=1 ; X_{5}=0 ; T=1 ; Y=1 ; Z=1 .
$$

In this case, there is no available water in this case. Yet, there remains a viable environment and the agent continues to exist. Why? In this case, the causal role that would have been performed by water is realised in the variable $T$, which represents the subsistence level of the synthetic molecule, causal water. If it is the case that $X_{1}=1 ; X_{2}=1 ; X_{3}=1 ; X_{4}=1$, then the agent will have a viable environment $(Y=1)$ if and only if $X_{5}=1$ or $T=1$. This latter disjunction was not available in the previous case because water performed a causal role that was not available in any other kind of condition. In this new case, by contrast, if there is no water $\left(X_{5}=0\right)$ then, there will be a subsistence level of causal water, since $T=\neg X_{5}$.

The preceding analysis has shown that equations and graphs can be used to model features of the environment required for the continued existence of an agent. This causal framework illustrates the idea that basic environmental conditions are required for this purpose because they afford the agent with an objective causal role that is not available in any other kind of environmental condition. These causal conditions must be met for 
the continued existence of agents. To put it more precisely, we can define a basic environmental condition as follows:

Definition 1: Basic Environmental Condition for an Agent

$\mathrm{x}$ is a basic environmental condition for agent $\alpha$ in environment $\mathrm{E}$ at time $t \leftrightarrow$ if all variables other than $\mathrm{x}$ were held fixed at their values at $t$, and $\mathrm{x}$ were removed from $\mathrm{E}$, then $a$ would cease to exist at $t$ (or shortly after $t)^{14}$

Definition 1 is a good start. However, ecological economists and sustainability scientists more broadly are generally concerned with conserving the stock of critical natural capital, not for the continued existence of any specific individuals, but for a group of agents. ${ }^{15}$ Thus, consider the following definition of a basic environmental condition, which relativises essential conditions to a group:

Definition 2: Basic Environmental Condition for a Group

$\mathrm{x}$ is a basic environmental condition for a group $\mathrm{G}$ in environment $\mathrm{E}$ at time $t \leftrightarrow$ if all variables other than $\mathrm{x}$ were held fixed at their values at $t$, and $\mathrm{x}$ were removed from $\mathrm{E}$, or completely destroyed, then at least some members of $\mathrm{G}$ would cease to exist (or shortly after $t){ }^{16}$

The only difference between Definition 1 and Definition 2 is that the former defines a basic environmental condition relative to an individual while the latter defines a basic environmental condition relative to a group. Both definitions are compatible with specifying critical natural capital specified with equations and graphs, as shown above.

Equations and graphs sharpen the concept of critical natural capital (Condition (1) specifically), but it should be apparent that they cannot identify or confirm the existence of basic environmental conditions. This is an empirical question that is to be answered by the best earth and life science available. Ideally, these sciences would be capable of establishing - on independent grounds - each exogenous variable that is essential to the dependent variable. In less ideal circumstances, one might ask the following question: what does the relevant empirical evidence suggest about the existence of basic environmental conditions, as outlined in Definition 1 and Definition 2? Which environmental features and processes, if any, are critical or essential to the continued existence of, for example, our species? Might this empirical evidence also serve to improve Definition 2?

Arguably, the most well-known contemporary scientific research on crucial or essential environmental conditions - on a global scale - is due to Johan Rockström et al. (2009a, 2009b). These earth scientists have convincingly argued that there is a 'safe operating space' for humanity constituted by various biophysical subsystems and processes on earth, including 'climate change,' the 'rate of biodiversity loss,' 'stratospheric ozone depletion.' Each subsystem or process is listed in Table 1, below. Rockström et al. (2009b, 473) identify and quantify parameters and boundaries for each of them.

Consider, for example, climate change. The parameters for this process are (i) atmospheric carbon dioxide concentration and (ii) change in radiative forcing and the boundaries are estimated to be 350 parts per million by volume and 1 watt per metre squared, respectively. On Rockström et al.'s account, each planetary boundary associated with a different earth-system process is a threshold. If humanity remains below these thresholds, then it is poised to remain within the 'safe operating space' that has been characteristic of the current epoch of geologic time (that began approximately 12,000-11,500 years ago). Transgressing any of these thresholds, on the other hand, is expected to result in 
Table 1. Planetary Boundaries.

\begin{tabular}{|c|c|c|c|c|}
\hline Earth-System Process & Parameters & Boundary & $\begin{array}{l}\text { Current } \\
\text { Status }\end{array}$ & $\begin{array}{l}\text { Pre- } \\
\text { Industrial } \\
\text { Value }\end{array}$ \\
\hline \multirow[t]{2}{*}{ Climate Change } & $\begin{array}{l}\text { (i) Atmospheric carbon dioxide concentration } \\
\text { (parts per million by volume) }\end{array}$ & 350 & 387 & 280 \\
\hline & $\begin{array}{l}\text { (ii) Change in radiative forcing (watts per metre } \\
\text { squared) }\end{array}$ & 1 & 1.5 & 0 \\
\hline Rate of Biodiversity Loss & $\begin{array}{l}\text { Extinction rate (number of species per million } \\
\text { species per year) }\end{array}$ & 10 & $>100$ & $0.1-1$ \\
\hline $\begin{array}{l}\text { Nitrogen cycle (part of a } \\
\text { boundary with the } \\
\text { phosphorus cycle) }\end{array}$ & $\begin{array}{l}\text { Amount of N2 removed from the atmosphere for } \\
\text { human use (millions of tonnes per year) }\end{array}$ & 35 & 121 & 0 \\
\hline $\begin{array}{l}\text { Phosphorus cycle (part of a } \\
\text { boundary with the } \\
\text { nitrogen cycle) }\end{array}$ & $\begin{array}{l}\text { Quantity of } P \text { flowing into the oceans (millions of } \\
\text { tonnes per year) }\end{array}$ & 11 & $8.5-9.5$ & $\sim 1$ \\
\hline $\begin{array}{l}\text { Stratospheric Ozone } \\
\text { Depletion }\end{array}$ & Concentration of ozone (Dobson unit) & 276 & 283 & 290 \\
\hline Ocean acidification & $\begin{array}{l}\text { Global mean saturation state of aragonite in } \\
\text { surface sea water }\end{array}$ & 2.75 & 2.9 & 3.44 \\
\hline Global freshwater use & $\begin{array}{l}\text { Consumption of freshwater by humans ( } \mathrm{km} 3 \text { per } \\
\text { year) }\end{array}$ & 4,000 & 2,600 & 415 \\
\hline Change in land use & $\begin{array}{l}\text { Percentage of global land cover converted to } \\
\text { cropland }\end{array}$ & 15 & 11.7 & Low \\
\hline Atmospheric aerosol loading & $\begin{array}{l}\text { Overall particulate concentration in the } \\
\text { atmosphere, on a regional basis }\end{array}$ & TBD & & \\
\hline Chemical pollution & $\begin{array}{l}\text { For example, amount emitted to, or } \\
\text { concentration of persistent organic pollutants, } \\
\text { plastics, endocrine disrupters, heavy metals } \\
\text { and nuclear waste in, the global environment, } \\
\text { or the effects on ecosystem and functioning of } \\
\text { Earth system thereof }\end{array}$ & TBD & & \\
\hline
\end{tabular}

'unacceptable global environmental change' characterised by radical instability. Exceeding these planetary thresholds risks undermining the environmental pre-conditions for continued existence and, therefore, human development and well-being.

Suppose ex hypothesi that critical natural capital denotes the earth-system processes identified by the best earth science available, which is due to Rockström et al. (2009a, $2009 b)$. On this account, transgressing any of the planetary boundaries identified by Rockström et al. counts as depleting (or degrading) basic environmental conditions. Given this supposition, we are in a position to further refine our definition as follows:

Definition 3. Basic Environmental Condition for Group*

$\mathrm{x}$ is a basic environmental condition for group $\mathrm{G}$ in environment $\mathrm{E}$ at time $t \leftrightarrow$ if all variables other than $\mathrm{x}$ were held fixed at their values at $t$, and $\mathrm{x}$ were depleted or degraded beyond a critical threshold (identified by the best natural science available), then there is a non-trivial positive probability, $p>0$, that some members of G would cease to exist at $t$ (or shortly after $t$ ).

How does Definition 3 measure up to the desiderata outlined at the end of Section 2? This definition identifies basic environmental conditions and makes explicit why instances of critical natural capital have no substitutes. Moreover, the equations and graphs used to model basic environmental conditions specify the causal conditions that would need to be satisfied by any potential substitute. Basic environmental conditions are distinctive because they perform causal roles unavailable in any other kind of environmental condition. Definition 3 is also consistent with the probabilistic nature of modelling the 
earth's planetary boundaries and expected consequences of transgressing them. Without pretending that Definition 3 is the only way to specify Condition (1), it does represent a significant improvement over the available alternatives.

\section{Modelling the Conservation of Critical Natural Capital}

The previous section specified Condition (1) from Section 2 with equations and graphs and proposed a new definition of the objective environmental conditions that must be satisfied for the continued existence of an agent or group. The primary purpose of this section is to elucidate Condition (2) in the context of environmental decision-making. What does it mean for the special parts of nature denoted by critical natural capital to be 'highly valued' or 'sacred' and how might one formally model the conservation of these essential parts of the environment ${ }^{17}$

Standard cost-benefit analysis (CBA) or the 'ecosystem services approach,' has been embraced by many ecological economists and their life scientist colleagues because it is believed that a direct appeal to the economic benefits of natural capital and ecosystem services is the best strategy for conserving such features and processes of the environment (Costanza et al. 1997; Daily 1997; Sen 2000). However, critics have argued that this approach cannot properly capture the 'no trade-offs' reasoning that is characteristic of making decisions about significant or 'priceless' parts of the natural environment (Ackerman and Heinzerling 2002; McCauley 2006). This critique is particularly salient when it comes to the question of modelling conservation decisions about non-negotiable parts of the environment deemed essential for the continued existence of our species. It seems reasonable to suppose that any formal decision-making model should aim to represent this 'priceless' aspect of the environment, especially when such parts have been degraded or depleted beyond the thresholds identified by Rockström et al. (2009a, 2009b).

As a first attempt, one might interpret 'priceless' in this context as assigning critical natural capital with absolute infinite value. Indeed, the main alternative to CBA or the ecosystem services approach is a deontological framework that employs infinite values to represent the no trade-offs approach that is characteristic of some environmental decisionmaking. ${ }^{18}$ By proposing a decision-making model that assigns positive infinite value to the conservation of critical natural capital, for example, one secures a non-negotiable commitment to conserve this subset of the environment. The critical natural capital theorist, Paul Ekins, effectively endorses this approach when he states, 'critical ecosystems and ecological features must be absolutely protected to maintain biological diversity' (Ekins et al. 2003, 176). Similarly, the ecological economist, Joshua Farley (2008) has also argued that, beyond a certain threshold, the stock of critical natural capital possesses infinite value.

Absolute infinite utilities decision-making models bring deontological intuitions into standard decision theory by allowing the utility function (that represents an agent's preferences) to take the values $+\infty$ and $-\infty$, in addition to finite real values.

Consider two examples: Climate Change and Stratospheric Ozone Depletion.

Example 1: Climate Change. Suppose the utility of unchecked climate change $=u$ (unchecked climate change) $=-\infty$ : the total consequence of unchecked climate change caused by anthropogenic greenhouse gas emissions is infinitely bad. We can reasonably 
assume that $\operatorname{Pr}($ unchecked climate change $\mid$ business as usual $)=p>0$. Then, we would calculate expected utility as follows.

$$
\begin{aligned}
E U(\text { business as usual }) & =p \cdot u(\text { unchecked climate change })+(1-p) \cdot u(\text { finite gain }) \\
& =p(-\infty)+(1-p)(\text { finite })=-\infty
\end{aligned}
$$

The expected utility of proceeding with business as usual is $-\infty$. Therefore, this activity should be rejected if there is any positive chance of experiencing the consequences of unchecked greenhouse gas emissions, which is infinitely bad. This prescription to conserve critical natural capital and avoid catastrophic climate change appears to be the result that proponents of strong sustainability wish to obtain.

Example 2: Stratospheric Ozone Depletion. Represent the utilities of the relevant outcomes as follows:

$$
\begin{aligned}
u(\text { The ozone is destroyed }) & =-\infty \\
u(\text { The ozone remains intact }) & =I(\text { a positive finite number })
\end{aligned}
$$

Now, suppose $\operatorname{Pr}$ (The ozone is depleted $\mid$ Do nothing $)=p>0$; the ozone's depletion, if nothing is done, has a small positive probability $p$.

Given these assumptions, the expected utility of doing nothing is $-\infty$ :

$$
\begin{aligned}
E U(\text { Do nothing }) & =p \cdot u(\text { ozone is destroyed })+(1-p) \cdot u(\text { ozone remains intact }) \\
& =p(-\infty)+(1-p) I \\
& =-\infty
\end{aligned}
$$

On the foregoing absolute infinite utility model, something should be done to avoid any positive chance that the ozone is depleted. Both examples - Climate Change and Stratospheric Ozone Depletion - appear to show that assigning absolute infinite value to critical natural capital is a promising conservation strategy.

Unfortunately, there are at least three interrelated problems with formalising the notion of absolute infinite value for environmental decision-making (Colyvan, Justus, and Regan 2010). First, suppose that for both options in Stratospheric Ozone Depletion (do nothing or do something to prevent ozone depletion) there is a positive probability that the ozone is destroyed and a positive probability that the ozone remains intact. In such a case, the infinite utilities model would provide no guidance because the expected utility of both options would be $-\infty$. There would be no basis for choosing between acts that yield equal expected utility.

Second, other things being equal, it seems reasonable to suppose that saving more critical natural capital is more valuable than saving less of it, especially beyond a 'planetary boundary.' Yet, if one assigns 'exceeding the climate change planetary boundary' with absolute infinite negative value, then barely exceeding the boundary and exceeding it by a large quantity has equal value. After all, two infinitely valued items possess equal value.

Consider Climate Change again. Let $B=$ Barely exceeding the climate change boundary (atmospheric carbon dioxide concentration is $351 \mathrm{ppm}$ ) and $F=$ Far exceeding the climate change boundary (atmospheric carbon dioxide concentration is $551 \mathrm{ppm}$ ). The problem here is that $B=F=-\infty$, but $u(\mathrm{~B})$ is clearly preferable to $u(\mathrm{~F})$. The absolute infinite-utilities 
model fails to discriminate between outcomes, $B$ and $F$. As Mark Colyvan and his coauthors point out, absolute infinite value is insufficiently discriminative of salient outcomes (Colyvan, Justus, and Regan 2010, 225).

Third, the absolute infinite utilities model is characterised by the issue of probability swamping. If conserving the ozone layer were to be assigned absolute infinite value, then any action with even the slightest positive probability of yielding this outcome will possess infinite expected utility. Therefore, actions with both high and low probabilities of conserving the ozone would have the same expected utility. Yet, indifference between these actions is the incorrect result. Why? Other things being equal, an action with a higher probability of bringing about an infinitely valuable outcome is preferable to an action with a lower probability of yielding the same outcome.

Consider an example. Let $D=$ Destruction of the ozone layer and $\mathrm{u}(D)=-\infty$. Let $P$ represent the option of passively doing nothing and $I$ represent active intervention to protect the ozone layer. Assume that $\operatorname{Pr}(D \mid P)=0.95$ and $\operatorname{Pr}(D \mid I)=0.01$. We can calculate the expected utility of each action as follows:

$$
\begin{aligned}
E U(P) & =(0.95)-\infty \text { and } \\
E U(I) & =(0.01)-\infty
\end{aligned}
$$

In this case, act $I$ is preferable to act $P$ because this option would result in a much lower probability of destroying the ozone layer, which possesses negative infinite value. Yet, the absolute infinite-utilities model prescribes indifference between $I$ and $P$. This result is counter-intuitive at best.

These problems and other issues with formalising absolute infinite value have led some scholars to argue that it is a mistake to assign any parts of the natural environment with infinite value (Colyvan, Justus, and Regan 2010). However, all is not lost. Others have shown that so long as one means relative infinite value - not absolute infinite value then we can model the priority of conserving significant parts of the natural environment while avoiding the problems just mentioned (Bartha and DesRoches 2017). I will adopt the same approach here by showing how relative infinite value can be used to model the conservation of critical natural capital, specifically. I will begin by introducing key features of relative utility theory (RUT), a theory pioneered by Paul Bartha (2007). ${ }^{19}$ To this end, consider the following notation:

- Weak preference. $B \geqslant A$ means $B$ is at least as good as $A$.

- Strict preference. $B>A$ means that $B$ is strictly preferred to $A$.

- Indifference. $\mathrm{B} \approx \mathrm{A}$ means that the agent is indifferent between $\mathrm{B}$ and $\mathrm{A}$.

- Gambles. $[\lambda \mathrm{B},(1-\lambda) \mathrm{Z}]$ is the gamble that gives the agent chance $\lambda$ of winning $\mathrm{B}$ and chance $(1-\lambda)$ of winning $Z$, where $0 \leq \lambda \leq 1$.

The starting point for RUT is the following proposition, which holds for any agent whose preferences satisfy the standard axioms apart from Continuity, which states that for any three outcomes Z, A and B such that B is preferred to A and A is preferred to Z, the agent must be indifferent between $A$ and some gamble between $B$ and $Z$ (Fishburn 1974). ${ }^{20}$

Proposition. If $B>A>Z$, then there is a unique number $\lambda, 0 \leq \lambda \leq 1$, such that the agent prefers $A$ to any gamble $[p B,(1-p) Z]$ when $p<\lambda$ and prefers $[p B,(1-p) Z]$ to $A$ if $p>\lambda$. 
Proposition is a weakening of Continuity. To see why, consider Figures 5 and 6 below. Gambles between $Z$ and $B$ are represented as points along the interval from $Z$ to $B$. The probability $\lambda$ of winning $B$ is represented as a proportion of the total interval. Given an outcome $A$ that is intermediate between $Z$ and $B$, an agent whose preferences satisfy Continuity will always be able to find some gamble in this interval that is equivalent to $A$ (i.e. such that the agent is indifferent between $A$ and the gamble).

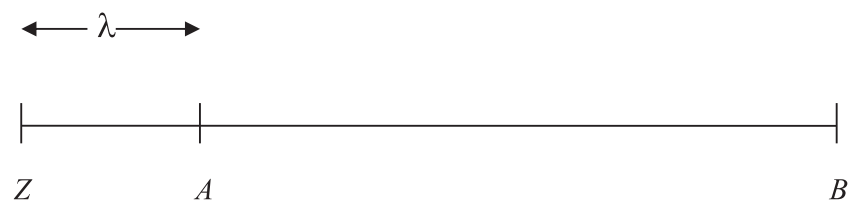

Figure 5. Continuity.

For the agent whose preferences satisfy Continuity, it is impossible to prefer any outcome infinitely relative to another. ${ }^{21}$ Suppose that $B$ is strictly preferred to $A$ and $A$ is strictly preferred to $Z$, as shown in Figure 5. With Continuity there is always a value $\lambda$ strictly between 0 and 1 such that the agent is indifferent between $A$ and $[\lambda B,(1-\lambda) Z]$.

Here is the picture for the case when the agent's preferences violate continuity:

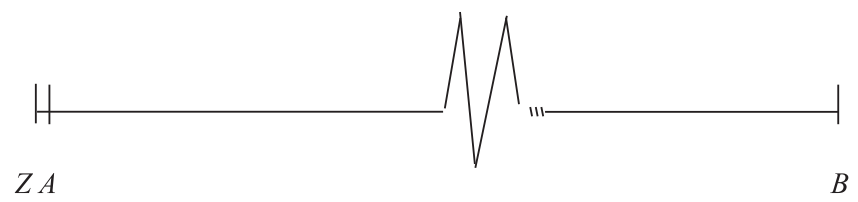

Figure 6. Violation of Continuity.

The zigzag line in Figure 6 indicates a discontinuity in the agent's preferences. The outcome on the right side, $B$, is preferred infinitely to the outcome on the left side, $A$, given a base-point $Z$, which is the losing (worst) outcome. ${ }^{22}$

What is a relative utility function? A relative utility function, $\mathrm{U}(\mathrm{A}, \mathrm{B} ; \mathrm{Z})$, is a three-place function defined whenever $A \geqslant Z$ and $B \geqslant Z$, with $0 \leq U(A, B ; Z) \leq \infty$. $U(A, B ; Z)$ is the utility of $A$ relative to $B$ with base-point $Z$. A relative utility function may be pictured as the 'ratio' of the utility interval Z-A to the interval Z-B, as depicted in Figures 5 and 6 above.

The following are three special cases of the relative utility function that will be useful when applying RUT to examples of critical natural capital:

Case 1: Relative Infinite Utility.

$\mathrm{U}(\mathrm{B}, \mathrm{A} ; \mathrm{Z})=\infty$ iff $[p \mathrm{~B},(1-p) \mathrm{Z}] \geqslant \mathrm{A}$ for $0<p \leq 1$.

Proposition enables one to meaningfully define relative infinite utility as a three-place relation, in terms of a base-point. Let $A, B$, and $Z$ be any three outcomes, where $B \geqslant A \geqslant$ $Z$. An agent values $B$ infinitely relative to $A$ and base-point $Z$ if

$$
[\lambda B,(1-\lambda) Z] \succeq A \text { for any } \lambda>0
$$


This means that the agent would give up A for any bet that gives a positive chance, however small, of gaining $\mathrm{B}$. Any gamble between $\mathrm{B}$ and $\mathrm{Z}$ which offers a positive probability of B is infinitely preferred to A. Figure 6 above shows that the 'distance' from $Z$ to $B$ is infinitely greater than the distance from $\mathrm{Z}$ to $\mathrm{A} .^{23}$

Case 2: Zero relative utility.

$\mathrm{U}(\mathrm{A}, \mathrm{B} ; \mathrm{Z})=0$ iff $[p \mathrm{~B},(1-p) \mathrm{Z}] \geqslant \mathrm{A}$ for $0<p \leq 1$.

This is equivalent to Case 1 , (Figure 6 above). The only difference is that $A$ and $B$ have been swapped. Any gamble between $\mathrm{B}$ and $\mathrm{Z}$ that offers a positive probability of $\mathrm{B}$ is preferred to A.

Case 3: Relative utility of 1 .

$\mathrm{U}(\mathrm{A}, \mathrm{B} ; \mathrm{Z})=1$ iff $\mathrm{B} \geqslant[p \mathrm{~A},(1-p) \mathrm{Z}]$ and $\mathrm{A} \geqslant[p \mathrm{~B},(1-p) \mathrm{Z}]$, for $0 \leq p<1$.

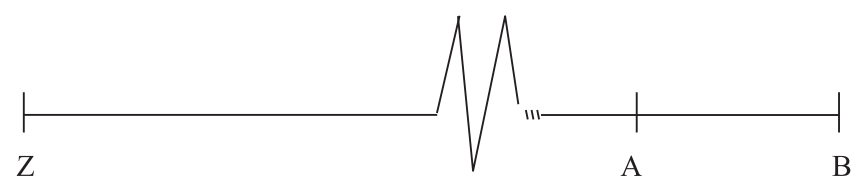

Figure 7. Relative Utility of 1.

In this case, the agent prefers $B$ to any non-trivial gamble between $A$ and $Z$, but also prefers A to any non-trivial gamble between $B$ and $Z$. Figure 7 shows that although $B$ is strictly preferred to $A$, the agent is unwilling to take any chance of getting $Z$ if she can have $A$ for sure. The distance from $\mathrm{Z}$ to $\mathrm{A}$ or $\mathrm{Z}$ to $\mathrm{B}$ is infinitely greater than the distance from $\mathrm{A}$ to $\mathrm{B}$.

\section{Applying RUT to Examples}

With the basic details of RUT behind us, we are now in a position to model decisionmaking that concerns critical natural capital.

Example 1.1: Stratospheric Ozone Depletion*: Let $H \equiv$ Half the ozone is saved, $W \equiv$ The whole ozone is saved, and let $A \equiv$ The ozone layer is destroyed. Let $Z$ be any basepoint worse than $A$. We can model the assumption that both $H$ and $W$ are infinitely better than $A$ by

$U(H, A ; Z)=U(W, A ; Z)=\infty$. We can picture these preferences as shown in Figure 8:

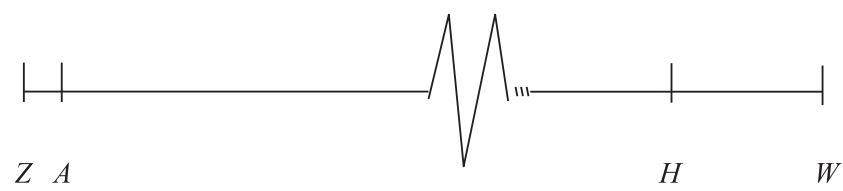

Figure 8. Stratospheric Ozone Depletion Example Option Set A.

We can also model the assumption that the agent is unwilling to trade $H$ for any gamble that might result in destroying the ozone layer: $U(H, W ; Z)=U(H, W ; A)=1$. In this case, 
$\mathrm{W}$ is strictly preferred to $\mathrm{H}$, but the agent is unwilling to take any action to bring about $\mathrm{W}$ if it increases the probability of destroying the whole ozone layer.

To discriminate between $H$ and $W$, one need only consider a different base-point, such as $Q \equiv$ One-quarter of the ozone is saved, as pictured below in Figure 9:

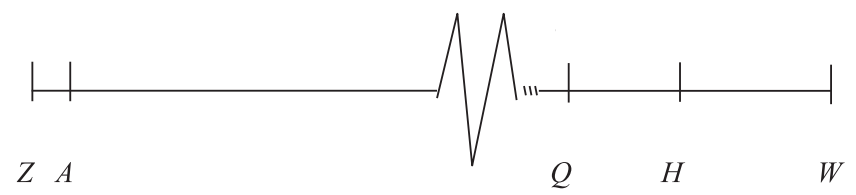

Figure 9. Stratospheric Ozone Depletion Example Option Set B.

In this case, we have:

$$
0<U(H, W ; Q)<1
$$

This value of the relative utility function means there is some non-trivial gamble between $W$ and $Q$ that is preferred to $H$. While $U(W, A ; Z)=U(H, A ; Z)=U(Q, A ; Z)$ $=\infty, \mathrm{W}$ is not infinitely preferable to $\mathrm{H}$, with base-point $\mathrm{Q}$ (the discontinuity is not located 'between' outcomes $Q, H$, and $W$ ). It is worth noting that, in a different decision context, where there is no risk of destroying the whole ozone layer, the agent may be willing to act that brings about the most preferred outcome, $\mathrm{W}$, even when there is some positive probability of making things a bit worse for the ozone layer. This kind of result is out of reach for views that assign absolute infinite utility to the ozone layer; however, this can be accommodated with relative infinite utility models.

Example 2.1: Climate Change*. We can model the same kind of decision for anthropogenic climate change. Let $M \equiv$ Mostly mitigated climate change, $A \equiv$ Avoided climate change and $B \equiv$ Business as usual (unbridled climate change). Let $Z$ be any base-point worse than $B$. Like the previous example, we can model the assumption that both $M$ and $A$ are infinitely better than $B$ by

$$
U(M, B ; Z)=U(A, B ; Z)=\infty .
$$

We can also model the assumption that we are unwilling to trade $M$ for any gamble that might result in $B$ :

$$
U(M, A ; Z)=U(M, A ; B)=1 .
$$

The challenge is to discriminate between $M$ and $A$, when there is a strict preference for $A$ over $M$. To show how this can be done, consider a different base-point, $S \equiv$ Slightly mitigated climate change. Suppose that the agent's preferences are pictured as follows in Figure 10:

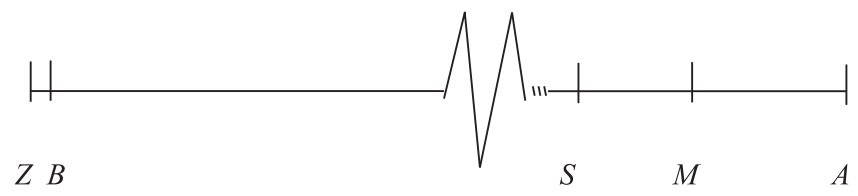

Figure 10. Climate Change Example Options. 
We now have:

$$
0<U(A, S ; M)<1 .
$$

There is some non-trivial gamble between $A$ and $S$ that is preferred to $M$. In the probabilistic version of the example, the choice is between the two gambles $\mathrm{G}_{A}=[p A,(1-p) B]$ and $\mathrm{G}_{M}=[p M,(1-p) B]$. If the base-point is $B$, then $U\left(G_{A}, G_{M} ; B\right)=1$ : we fail to discriminate between the two gambles, since both are infinitely better than $B$. But if instead the basepoint is $G_{S} \equiv[p S,(1-p) B]$, then $U\left(G_{A}, G_{M} ; G_{S}\right)=U(A, M ; S)$, a value between 0 and 1. Given a suitable choice of the base-point, RUT enables us to discriminate between the two gambles and clearly prescribes $G_{A}$ over $G_{M}$.

To summarise, this section has argued that assigning absolute infinite value to critical natural capital, a convention followed by some ecological economists, is a mistake in the context of modelling conservation decisions that affect critical natural capital. Be that as it may, as shown with examples 1.1 and 2.1 above, an alternative infinite utilities model - a relative infinite utility model - can avoid the problems associated absolute infinite value in formal decision-making models. By selecting an appropriate base-point, a relative utility model provides guidance, discriminates between outcomes, and avoids the issue of probability swamping (Colyvan, Justus, and Regan 2010).

\section{Conclusion}

Critical natural capital is central to the interdisciplinary science of ecological economics and yet the concept remains subject to immense confusion. The main purpose of this article was to show how this concept can be made clear and distinct. I suggested that the most promising definition type entails that an instance of natural capital is critical if and only if it is (1) required for continued existence and (2) 'highly valued.' This article specified both conditions. Section 3 specified Condition (1) with a structural model and proposed a new account of the objective environmental conditions, termed 'basic environmental conditions,' required for continued existence. This account, I argued, goes a long way to satisfy the desiderata outlined in Section 2. Critical natural capital qua basic environmental conditions makes explicit what it means for some environmental conditions to be essential for continued existence. Moreover, it is consistent with relevant empirical evidence and clearly identifies the conditions that would need to be satisfied for any object to potentially serve as a substitute for basic environmental conditions.

Section 4 wrestled with Condition 2, the distinctive kind of value assigned to the conservation of critical natural capital. While leading ecological economists have suggested that, beyond some threshold, critical natural capital possesses absolute infinite value, I showed that, in the context of formally modelling environmental decisions, ecological economists would be better served by modelling the priority of conserving critical natural capital with a relative infinite utility model. On this model, the conservation of critical natural capital possesses relative, not absolute, infinite value.

The chief purpose of this article was to specify the concept critical natural capital, not to resolve the debate between weak and strong sustainability. However, I will finish where I began - with a brief remark on this debate. What consequence, if any, does the account of critical natural capital proposed in this article have for this debate between weak and strong sustainability? If one interprets the proponents of weak sustainability as insisting 
that sustainability requires members of the present generation to sustain nothing in kind, and it turns out that critical natural capital denotes the earth subsystems and processes identified by Rockström et al. (2009a, 2009b), or something like them, then it would appear that weak sustainability is false in at least one important sense.

\section{Notes}

1. The International Society for Ecological Economics published the inaugural issue of Ecological Economics in 1989.

2. For the advancements made by ecological economists, see Christensen (1989); MartinezAlier and Røpke (2008a), (2008b); Røpke (2005).

3. For the origins of this debate, see Beckerman (1994), (1995); Daly (1995); 1997a; 1997b); Solow (1997); Stiglitz (1997). For a detailed overview of the debate between weak and strong sustainability, see Neumayer (2003).

4. The 'social scientific approach' to sustainability was originally motivated by The World Commission on Environment and Development (1987). This approach was pioneered by Robert M. Solow (1986) and subsequently developed by David Pearce et al. (1989).

5. Specifically, sustaining the aggregate level of capital over time requires following Hartwick's Rule whereby total net investment in capital remains above or equal to zero (Hartwick 1977, 1978). If net investment were to fall below this threshold, capital would be depleted and, because the stock of capital represents the productive capacity of an economy, production, along with the present and future human welfare that depends on it, would also decline (Arrow et al. 2004; 2010).

6. For additional arguments, see DesRoches (2019).

7. There is no consensus on the objects denoted by the concept of critical natural capital. Frequently cited examples include 'freshwater resources,' 'climate regulation' and 'fertile soils' (see Millenium Ecosystem Assessment 2005). Below, I will suppose ex hypothesi that the earth subsystem and processes identified by Johan Rockström et al. (2009a, 2009b) are instances of critical natural capital.

8. Rudolf de Groot et al. $(2006,221)$ consider some of the definitions listed here.

9. When proposing this particular definition, Pelenc and Ballet (2015) cite many other scholars likely to endorse it, including Ekins et al. (2003), Chiesura and de Groot (2003), de Groot et al. (2003) and Brand (2009).

10. For this purpose, I will mainly follow Christopher Hitchcock (2001).

11. Of course, the real epistemic benefit of equations and graphs is not merely the elegant representations of causal relations, but the clear and definite counterfactual reasoning they enable.

12. Clearly, the dependent variable $Z$ could also be made to represent the continued existence or non-existence of a group. This possibility is discussed below.

13. It is to be remarked that the model merely represents causal knowledge. The knowledge itself is to be obtained somewhere else (earth and life sciences). This issue is discussed below.

14. The symbol ' $\leftrightarrow$ ' should read as 'if and only if. This definition can be read in light of J.L. Mackie's $(1980,63)$ concept of a causal field: a set of background conditions, not completely specified but taken as fixed. The causal field fixes everything but some set of variables that one is interested in.

15. This group might consist of 'all humans (i.e. humanity) or for a given human population or interest group in a given situation' (de Groot et al. 2003, 190).

16. I will suppose an equal distribution of basic environmental conditions among members of $G$.

17. I will continue to suppose that critical natural capital denotes the earth-system subsystems, processes, and thresholds identified by Rockström et al. (2009a).

18. For more on the deontological approach and critical natural capital specifically, see Pearson, Kashima, and Pearson (2012); Baron and Spranca (1997); Tetlock et al. (2000).

19. For brevity, many details of RUT are omitted here. For further details, see Bartha (2007). My exposition of RUT closely follows Bartha and DesRoches (2017). 
20. For a rehearsal of the standard axioms, see Resnik, M. D.: 1987, Choices, University of Minnesota Press, Minneapolis.

21. Below, I define what it means to value B infinitely relative to A and Z.

22. Why invoke a base-point here? One cannot define relative utility using gambles (as done here) without specifying the two alternatives (i.e., B and Z). As will be made clear below, the preferability of some outcome $A$ over a gamble between $B$ and $Z$ will change depending on what the base-point is.

23. It is worth noting that because relative infinite utilities can be defined in terms of ordinary preferences between well-defined gambles, there is no need for calculations using positive or negative infinity.

\section{Acknowledgements}

I wish to thank Josh Abbott, John Beatty, François Claveau, Eric Desjardins, Allen Habib, Andrew Inkpen, Stefan Lukits, Roberta Millstein, Luis Mireles Flores, Chris Mole, John O’Neill, Charles Perrings, Margaret Schabas, Chris Stephens, Beckett Sterner and two anonymous reviewers for helpful conversations and comments on earlier versions of this article. Special thanks to Paul Bartha for his remarkable erudition. Any errors are mine.

\section{ORCID}

C. Tyler DesRoches (D) http://orcid.org/0000-0002-7318-6948

\section{References}

Ackerman, F., and L. Heinzerling. 2002. "Pricing the Priceless: Cost-Benefit Analysis of Environmental Protection." University of Pennsylvania Law Review 150 (5): 1553-1584.

Arrow, K., P. Dasgupta, L. Goulder, G. Daily, P. Ehrlich, G. Heal, S. Levin, et al. 2004. "Are We Consuming Too Much?” Journal of Economic Perspectives 18 (3): 147-172.

Arrow, K., P. Dasgupta, L. H. Goulder, K. J. Mumford, and K. Oleson. 2010. "Sustainability and the Measurement of Wealth.” Environment and Development Economics 17: 317-353.

Barbier, E. B. 2011. Capitalizing on Nature: Ecosystems as Natural Assets. Cambridge: Cambridge University Press.

Baron, J., and M. Spranca. 1997. "Protected Values." Organizational Behavior and Human Decision Processes 70: 1-16.

Bartha, Paul. 2007. “Taking Stock of Infinite Value: Pascal's Wager and Relative Utilities.” Synthese 154 (1): 5-52.

Bartha, P., and C. T. DesRoches. 2017. "The Relatively Infinite Value of the Environment." Australasian Journal of Philosophy 95 (2): 328-353.

Beckerman, W. 1994. “'Sustainable Development': Is it a Useful Concept?” Environmental Values 3 (3): 191-209.

Beckerman, W. 1995. "How Would You Like Your 'Sustainability', Sir? Weak or Strong? A Reply to My Critics.” Environmental Values 4 (4): 169-179.

Brand, F. 2009. "Critical Natural Capital Revisited: Ecological Resilience and Sustainability Development." Ecological Economics 68: 605-612.

Chiesura, A., and R. de Groot. 2003. "Critical Natural Capital: A Socio-Cultural Perspective." Ecological Economics 44: 219-231.

Christensen, P. P. 1989. "Historical Roots for Ecological Economics - Biophysical Versus Allocative Approaches.” Ecological Economics 1: 17-36.

Colyvan, M., J. Justus, and H. Regan. 2010. "The Natural Environment is Valuable but Not Infinitely Valuable." Conservation Letters 3: 224-228. 
Costanza, R., and H. Daly. 1992. "Natural Capital and Sustainable Development." Conservation Biology 6 (1): 37-46.

Costanza, R., R. d’Arge, R. de Groot, S. Farber, M. Grasso, B. Hannon, K. Limburg, et al. 1997. “The Value of the World's Ecosystems Services and Natural Capital." Nature 387: 253-260.

Daily, G. C. 1997. Nature's Services: Societal Dependence on Natural Ecosystems. Washington, D.C.: Island Press.

Daly, H. E. 1995. “On Wilfred Beckerman's Critique of Sustainable Development.” Environmental Values 4 (4): 49-55.

Daly, H. E. 1997a. "Georgescu-Roegen Versus Solow/Stiglitz." Ecological Economics 22: 261-266.

Daly, H. E. 1997b. "Reply to Solow/Stiglitz." Ecological Economics 22: 271-273.

Daly, H. E., and K. N. Townsend, eds. 1993. Valuing the Earth: Economics, Ecology, Ethics. Cambridge: MIT Press.

de Groot, R., L. Hein, C. Kroeze, R. Leemans, and D. Niemeijer. 2006. "Indicators and Measures of Critical Natural Capital.” In Sustainable Development Indicators in Ecological Economics, edited by P. Lawn, 221-245. Cheltenham, UK: Edward Elgar.

de Groot, R., J. Van der Perk, A. Chiesura, and Arnold van Vliet. 2003. "Importance and Threat as Determining Factors for Criticality of Natural Capital.” Ecological Economics 44: 187-204.

Dennett, D. C. 1996. Darwin's Dangerous Idea: Evolution and the Meaning of Life. New York: Touchstone.

DesRoches, C. T. 2019. “Some Truths Don't Matter: The Case of Strong Sustainability.” Ethics, Policy \& Environment 22 (2): 184-196.

Ekins, P., S. Simon, L. Deutsch, C. Folke, and R. de Groot. 2003. "A Framework for the Practical Application of the Concepts of Critical Natural Capital and Strong Sustainability." Ecological Economics 44: 165-185.

English Nature. 1994. Sustainability in Practice. Planning for Environmental Sustainability: Issue Number 1. Peterborough, UK: English Nature.

Farley, J. 2008. “The Role of Prices in Conserving Critical Natural Capital." Conservation Biology 22 (6): 1399-1408.

Fishburn, P. C. 1974. "Lexicographic Orders, Utilities and Decision Rules: A Survey." Management Science 20/11: 1442-1471.

Folke, C., M. Hammer, R. Costanza, and A. Jansson. 1994. "Investing in Natural Capital - Why, What and How?" In Investing in Natural Capital: The Ecological Economics Approach to Sustainability, edited by A. Jansson, M. Hammer, C. Folke, and R. Costanza, 1-20. Washington, DC: Island Press.

Functowicz, S. O., and J. R. Ravetz. 1994. "The Worth of a Songbird: Ecological Economics as a Post-Normal Science.” Ecological Economics 10: 197-207.

Georgescu-Roegen, N. 1971. The Entropy Law and the Economic Process. Cambridge: Harvard University Press.

Gowdy, J., and J. D. Erickson. 2005. "The Approach of Ecological Economics." Cambridge Journal of Economics 29: 207-222.

Halpern, J., and J. Pearl. 2000. Causes and Explanations: A Structural-Model Approach, Technical report R-266, Cognitive Systems Laboratory, University of California/Los Angeles.

Hartwick, J. M. 1977. "Intergenerational Equity and the Investing of Rents from Exhaustible Resources.” American Economic Review 67 (5): 972-974.

Hartwick, J. M. 1978. "Substitution Among Exhaustible Resources and Intergenerational Equity." Review of Economic Studies 45 (2): 347-354.

Hitchcock, C. 2001. “The Intransitivity of Causation Revealed in Equations and Graphs.” Journal of Philosophy 98 (6): 273-299.

Hueting, R., and L. Reijnders. 1998. "Sustainability is an Objective Concept." Ecological Economics 27 (2): 139-147.

Illge, L., and R. Schwarze. 2009. "A Matter of Opinion - How Ecological and Neoclassical Environmental Economists Think About Sustainability and Economics." Ecological Economics 68: 594-604. 
Lewontin, R. C. 1983. “Gene, Organism, and Environment.” In Evolution from Molecules to Men, edited by D. S. Bendall, 273-285. Cambridge: Cambridge University Press.

Mackie, J. L. 1980. The Cement of the Universe. Oxford: Oxford University Press.

Martinez-Alier, J., and I. Røpke, eds. 2008a. Recent Developments in Ecological Economics I. Northampton: Edward Elgar Publishing.

Martinez-Alier, J., and I. Røpke, eds. 2008b. Recent Developments in Ecological Economics II. Northampton: Edward Elgar Publishing.

McCauley, D. J. 2006. “Selling Out on Nature.” Nature 443: 27-28.

Millennium Ecosystem Assessment. 2005. Ecosystems and Human Well-Being: Synthesis. Washington: Island Press.

Neumayer, E. 2003. Weak Versus Strong Sustainability. Cheltenham: Edward Elgar.

Pearce, D. W., A. Markandya, and E. B. Barbier. 1989. Blueprint for a Green Economy. London: Earthscan Publications.

Pearl, J. 2000. [2009]. Causality: Causal, Reasoning, and Inference. New York: Cambridge University Press.

Pearson, L. J., Y. Kashima, and C. J. Pearson. 2012. "Clarifying Protected and Utilitarian Values of Critical Natural Capital.” Ecological Economics 73: 206-210.

Pelenc, J., and J. Ballet. 2015. "Strong Sustainability, Critical Natural Capital and the Capability Approach.” Ecological Economics 112: 36-44.

Resnik, M. 1987. Choices: an Introduction to Decision Theory. Minneapolis: University of Minnesota Press.

Rockström, J., W. Steffen, K. Noone, Å Persson, F. S. Chapin III, E. Lambin, T. M. Lenton, et al. 2009a. "Planetary Boundaries: Exploring the Safe Operating Space for Humanity." Ecology and Society 14 (2): 32.

Rockström, J., W. Steffen, K. Noone, Å Persson, F. S. Chapin, E. F. Lambin, and T. M. Lenton. 2009b. "A Safe Operating Space for Humanity." Nature 461: 472-475.

Røpke, I. 2005. "Trends in the Development of Ecological Economics: From the Late 1980s until the Early 2000s." Ecological Economics 55: 262-290.

Sen, A. 2000. "The Discipline of Cost-Benefit Analysis." Journal of Legal Studies XXIX: 931-952.

Solow, R. M. 1986. "On the Intertemporal Allocation of Natural Resources." Scandinavian Journal of Economics 88: 141-149.

Solow, R. M. 1993a. “An Almost Practical Step Towards Sustainability.” Resources Policy 19: 162172.

Solow, R. M. 1993b. “Sustainability: An Economist's Perspective.” In Economics of the Environment: Selected Readings, edited by R. Dorfman and N. S. Dorfman, 179-187. New York: W \& W Norton and Company.

Solow, R. M. 1997. “Reply: Georgescu-Roegen versus Solow/Stiglitz.” Ecological Economics 22: 267268.

Stern, D. 1997. "Interpreting Ecological Economics in the Neoclassical Paradigm: Limits to Substitution and Irreversibility in Production and Consumption." Ecological Economics 21: 197-215.

Stiglitz, J. 1997. “Reply: Georgescu-Roegen versus Solow/Stiglitz.” Ecological Economics 22: 69-70.

Tacconi, L. 1998. "Scientific Methodology for Ecological Economics." Ecological Economics 27: 91105.

Tetlock, P. E., O. V. Kristel, S. B. Elson, and J. S. Lerner. 2000. “The Psychology of the Unthinkable: Taboo Trade-Offs, Forbidden Base Rates, and Heretical Counterfactuals.” Journal of Personality and Social Psychology 78: 853-870.

Turner, R. K. 1993. "Sustainability: Principles and Practice." In Sustainable Environmental Economics and Management: Principles and Practice, edited by R. K. Turner, 3-36. London: Belhaven Press.

Victor, P. A. 1991. "Indicators of Sustainable Development: Some Lessons from Capital Theory." Ecological Economics 4: 191-213.

The World Commission on Environment and Development. 1987. Our Common Future. Oxford: Oxford University Press. 